\section{No. 4861 December 29, 1962}

more convenient to hold the instructional and test items fairly constant and to operate, on a separate display if nocessary, a variable supply of supplementary information and hints. In addition, it is useful to impose limits on the time allowod for assimilating instructions and rosponding to test questions. The time limits can then be differentially adjusted so that longer time is allowed in respect of items that the subject is likely (according to the machine's computations) to find difficult.

These two gambits have been successfully used in several commercial teaching machinos of which the best known is the $S A K I$ (Solatron Automatic Keyboard Instructor) device. This was pioneered by Gordon Pask for training operators on the 12-key 'Hollerith' card punch. Briefly, the system consists of a display unit that gives instructions and prompts, a keyboard which the trainee must operate (without looking at the koys), and an adaptive computer which 'senses' the characteristics of the student and adjusts the training programme to suit his noeds. The display unit consists of a back-lighted exercise card (containing four lines of 24 figures) and an urray of 12 lights laid out in the same spatial pattern as the 12 keys on the keyboard. Since some combinations of figures are harder to punch than others, the exercise cards are changeable and are graded with respect to difficulty.

The figuros on the exerciso card are illuminated one at a time (moving from left to right) and, for each figure that appears, a corresponding light shines in the 12-light array to indicato tho position of the key on the real keyboard. The trainee's task is to press the appropriate key within a given allowance. If he fails to do so, the figure is automatically replaced by the noxt figuro to the right, and the trainee is recorded as having mado a mistake. During the early stages of learning the figures move on rather slowly. However, as the traineo gains in spood and accuracy the waiting times become shorter, and the prompting lights (in the 12-light array) diminish in intensity. But this is done differentially, so that tho machine continues to wait longer and to give prompts on those keys which porsist in giving difficulty. Furthermoro, it will slow down and restore prompts in respect of any key on which the traineo has a sudden relapse. Whereas tho simpler teaching machines tako corroctivo action on the basis of just ono rosponso, $S A K I$ adjusts its programme in accordance with an integrated performanco measure (based on speed and accuracy) assured over a whole series of rosponses. SAKI also 'paces' the student by adjusting difficulty and time pressure so that he is always working near the limit of his ability.

This machino uses a technique that tends to minimize the amount of useful information gained about the student. For if the student were to be given easy problems that almost everyone could solve, little would be learned about him. Convorsoly, little is learned by loading him with problems which are beyond his capacity. An optimal 'in-between' stratogy is to start with easy problems and to step up their difficulty. But this moans the student is most likely to revenl his incipient weaknesses without, at the same time, wanting to withdraw from the situation. By keeping the student around the threshold of his ability, his attention tends to be completely absorbod by the instructional material presented, and this renders him controllable for toaching purposes. As a further refinement the teaching machine may conceal the fact that it has detected a weakness in tho student; in this way it can continue to probe for information without losing the student's goodwill.

The teaching principles embodied in $S A K I$ are entirely genoral. Adaptive machines have boen built to instruct such diverse skills as typing, faultfinding and equipment maintenance, radar training, pattern recognition, and inductive and deductivo reasoning. In every case the same dynamic rolationship is established between the student and machine, so that the student is spurred on to greater and greater efficiency under optimally congenial conditions. There are theoretical reasons for supposing that no teaching method could be botter than this.

\title{
THE COMMONWEALTH SCIENTIFIC AND INDUSTRIAL RESEARCH ORGANIZATION (AUSTRALIA)
}

\begin{abstract}
$\mathrm{T}$ HE fourteenth annual report of the Commonwealth Scientific and Industrial Research Organization (Australia)*, covering the year onded June 30, 1962 , bosides the general review and brief survey of progress in research, includes lists of papers published during the yoar and details of membership of the Advisory Council, State Committees and staff. Of total expenditure of $£ 12,089,389, £ 1,122,354$ was on capital works, and of $£ 10,967,035$ spent on investigations, $£ 174,814$ went to the Commonwealth Agricultural Buroaux and other outside bodies. Expenditure on the Animal Research Laboratories was $£ 1,190,120$; on plant research, $£ 994,727$; ontomology, $£ 434,183$; soils research, $£ 360,048$; food preservation, $£ 390,294$; forest products research, $£ 426,306$; chemical research laboratories, $£ 981,747$; tho National Standards Laboratory, $\$ 836,017$; fisheries and oceanography, £257,412; building research, £208,046;

* Commonwealth Sejentinc and Industrial Researeh Organization Australia. Fourteenth Annual Report, 1961-62. Pp. iv $+153+10$ plates. (Melbourne and Sydney: Commonwealth Selentific and Industrial Research Organization, 1962).
\end{abstract}

radiophysios, $£ 429,664$; wool research, $£ 711,331$; land

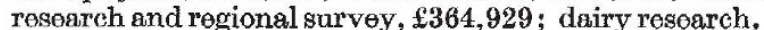
$£ 165,698$; tribophysics, $£ 125,988$; fuel research, $£ 299,203$; and wildlife survey, $£ 187,254$. During the year, 35 junior and 41 senior postgraduate studentships were awarded and 10 overseas studentships. The $210-\mathrm{ft}$. radio-telescope for the Division of Radiophysics was officially commissionod on October 31,1961 .

Among the legumes and grasses of value to the grass industry as a result of the work of the Tropical Pastures Division are Lotononis bainesii, Siratro and Numbank buffel grass, while 100 per cent prevention of Phalaris staggers was obtained by administration of heavy cobalt pollots along with steel grinders to cattle grazing on Phalaris tuberosa. A method of soil analysis has been developed to give a diroct assessment of the phosphate fertilizer requirements of wheat for the most economic return, and field experimonts indicate that the average rate of application of superphosphate in the southern wheat belt of New South Wales could be increased to give returns of 
£2-3 per acre. A broad-scale field survey of the Tipperary region in the Northern Territory was completed during the year, and inoculation of pelleted seed with very high numbers of nodule bacteria by a multi-step process has produced up to 100 per cont nodulation of subterranean and crimson clovers sown on skeletal hill soils where the standard commercial inoculation is without effect. A technique has been developed permitting separation of composite particles of silica from a plant without damaging the structure or altering the composition of the particles; detailed studies of the silica from the vegetative and reproductive parts of the mature oat have revealed that the walls of all types of epidermal cells except cork cells are impregnated with silica.

Studies with radioactive phosphorus have shown that roots of Pinus radiata infected with mycorrhizal fungi take up larger amounts of nutrient and suggest that particularly efficient fungi can be selected for inoculating forestry nurseries. Evidence has been obtained that the cellular organelles (mitochondria) associated with the production of adenosine triphosphate in plant tissues of fruits become heavily labelled by the methyl group of methionine, mostly in the lipid fraction, and, in particular, plant sterols and ubiquinone have been isolated and found to be radioactive. The natural enzymatic formation of ironporphyrin complexes is being investigated, and the structure of the anti-fungal compound, pisatin, isolated from infected peas, has been established as 3-hydroxypterocarpin.

As little as 0.01 per cent of decontaminating proteins have been detected in the protein hormones that control wool growth by zone electrophoresis on starch gel, and the breakdown of metabolic efficiency incurred by vitamin- $\mathrm{B}_{12}$ deficiency in sheep has been located in the chomical transformation through which propionic acid is launched into the energy-producing cycle, that is, in the isomeric conversion of the intermediate methylmalonic acid to succinic acid. An investigation of the pyrrolizidone alkaloids occurring in plants indicates that those causing chronic or acute liver damage when eaten by animals have similarities in the structure of their molecules and that their effects on the cell nuclei resemble the effects of the so-called biological alkylating agents. An investigation of the flight behaviour of the Australian plague locust early in 1962 indicated that the occurrence of numerous flying swarms in the 'outbreak areas' is not necessarily a prelude to a widespread outbreak.

A laboratory has been established at Canberra, where the alarm and distress signals of several species of birds have been recorded and prepared for analysis, and where aggressive, territorial, food finding, mating and other calls are being studied in relation to the behaviour and social organization of birds. An infrared design of a single-effect solar still with a plastic base, producing about $10 \mathrm{gal}$. of distilled water on a clear summer day, at an estimated cost of $£ 1$ per 1,000 gal., is undergoing tests and a prototype for use in isolated areas is being built. The illumination of pedestrian crossings by floodlighting the pedestrians from the directions of the approaching traffic streams has been successfully tested in two experimental installations. Four protein preparations have now been extracted from wool fibre; the two with a high content of sulphur have much smaller molecules than the two with a low content of sulphur and are basic in nature in the original fibre, whereas the lowsulphur proteins are acidic. Ultra-violet radiation in sunlight splits the disulphide bonds of cystine, and chemical investigations of pure cystine suggest that, in presence of air, it is the bond between the carbon and sulphur atoms that is split in neutral and alkaline solutions, whereas in acid solutions the bond between the two sulphur atoms is split.

By spray drying an emulsion of butter fat in a solution of sodium caseinate and non-fat milk solids a new dairy product, powdered butter, has been produced, containing 80 per cent of fat with 15 per cent, of milk protein and some mineral salts, which is more convenient than normal butter for use in cakes, frying batter and ice-cream. A long-term investigation is in progress of the physical factors important in bulk wheat storage, particularly heat and moisture transfers within the bulk. A new humidity-sensitive element, consisting essentially of a thin layer of selenium dioxide, the elestrical resistance of which responds to changes in the humidity of the surrounding atmosphere, has been developed with rapid response and good accuracy even at more than 90 per cent relative humidity and near the freezing point. Completion of the first survey of the distribution of ozone in the southern hemisphere has shown that the distribution differs significantly from that in the northern. hemisphere. Mathematical methods for removing the effect of the spread of energy and greatly reducing the random scatter in ionization investigations have been devised by utilizing certain redundancies in the measured data. An instrument has been devised which measures simultaneously the atmospheric distortion in measurements of the total light from a star, its position and its image.

\section{UNIVERSITY DEVELOPMENT IN INDIA}

\begin{abstract}
$\mathrm{T}$ HE Statistical Report, 1961-62, on University Development in India*, prepared by the Statistics Section of the University Grants Commission, New Delhi, is based on returns received from the 53 universities recognized in July 1962; of these 15 are unitary, 2 federal and 36 affiliating, while there are 5 other institutions, including the Indian Agricultural Research Institute, New Delhi, and the Indian Institute of Science, Bangalore, deemed to be universities under the University Grants Commission Act

* University Development in India: A Statistical Report, 1961-62 Pp. vii +76. (New Delhi: University Grants Commission, 1962.) Pp. vii +76 . 5.
\end{abstract}

of 1956. The number of teaching departments was 904 , including 233 in science, 80 in medicine, 33 in engineering and 17 in technology, and the total number of students enrolled was 980,380 , of whom 841,580 were in the 1,676 affiliated colleges and 138,800 in the teaching departments: there were also 169,627 women students; these totals represent increases of 13 per eent and 12 per cent, respectively, on the number of students in 1960-61. The Universities of Agra, Bombay, Calcutta, Kerale, Madras and the Punjab together account for $40 \cdot 1$ per cent of the total compared with 41.8 per cent in 1960-61, and 